\title{
ESTRATEGIAS PARA LA CONSERVACIÓN DEL SITIO SAGRADO “HATUN PUKYO", COMUNIDAD CUATRO ESQUINAS, PARROQUIA SAN RAFAEL DE LA LAGUNA.
}

\author{
STRATEGIES FOR THE CONSERVATION OF THE SACRED SITE "HATUN \\ PUKYO", CUATRO ESQUINAS COMMUNITY, SAN RAFAEL DE LA LAGUNA.
}

Elsa Susana Cachimuel Aguilar, Ing. Ingeniera en Desarrollo social y cultural (Ecuador). Labora en la Universidad de Otavalo, Ecuador. elsacachimuel92@gmail.com

Lidia Inés Díaz Gispert, PhD.

Doctora en Ciencias Económicas (Cuba). Docente a Tiempo Completo de la Universidad de Otavalo, Ecuador. lidiadg2914@hotmail.com

\section{ARTÍCULO DE INVESTIGACIÓN}

Recibido: 11 de abril de 2019.

Aceptado: 28 de junio de 2019.

\section{RESUMEN}

La difusión de los saberes ancestrales es una línea importante de acción dentro de la política trazada por las Naciones Unidas, para conservar las raíces históricas y la identidad de las naciones. El Estado ecuatoriano desarrolla políticas para rescatar los saberes ancestrales que conforman el soporte de toda la riqueza espiritual y material de su sociedad. A tales efectos, la investigación se desarrolla en la comunidad Cuatro Esquinas, parroquia San Rafael de la Laguna, cantón Otavalo y tiene como objetivo la preservación del sitio sagrado "Hatun Pukyo". La recolección de la información se obtuvo mediante la aplicación de la técnica de entrevista y encuesta. La sistematización de los resultados se realizó utilizando el programa estadístico SPSS versión 24, obteniéndose una matriz de propuesta de estrategias para la conservación de "Hatun Pukyo", en la cual se definen cada una de las actividades principales que sirvieron de base para su elaboración. Además, se diseñó un procedimiento estructurado de forma lógica en cuanto a pasos a seguir, para la consecución de la 
conservación de los sitios sagrados, susceptible de ajustarse a otras comunidades donde exista presencia de estos, lo que estimula a investigaciones posteriores de temas relacionados a problemas ambientales, patrimonio cultural y natural, turismo comunitario, entre otros proyectos.

Palabras clave: Sitio ancestral, comunidad, estrategias.

\section{ABSTRACT}

One of the United Nations important action targets within its policies to preserve the historical roots and the nations' identity is the dissemination of the ancestral knowledge. Among such policies, the Ecuadorian State is engaged in the rescuing of the ancestral knowledge that comprises all the spiritual and material wealth background of its society. The paper reports a research developed in the Cuatro Esquinas community at San Rafael de la Laguna Parish, in the County of Otavalo. Its objective was to preserve the sacred site of "Hatun Pukyo". The information was gathered with the application of the interview and survey techniques. The results systematization was obtained with the help of the statistical program SPSS, version 24 , which allowed getting a matrix for the strategies proposal for the preservation of the "Hatun Pukyo". Each of the main activities that served as basis for the proposal is defined. Moreover, a structured procedure was designed for the achievement of sacred sites that is subject to adjustment for other communities with presence of similar wealth, depending on their characteristics and specific objectives. At the same time the research leaves a challenge to other researchers to work on similar environmental, heritage, cultural, natural and community tourist issues, among other projects.

Keywords: Ancestral site, community, strategies

\section{INTRODUCCIÓN}

Ecuador, país de América del Sur, es pródigo respecto a sus riquezas naturales y culturales. Sus recursos juegan un papel significativo en el contexto nacional, natural y cultural del país. Sus regiones conformadas por pueblos y nacionalidades indígenas constan de patrimonios tangibles e intangibles, con un valor intrínseco que se debe preservar y difundir. AI respecto ICOMOS citado por Friere (2012) define patrimonio como: 
Conjunto de elementos que incluyen entornos naturales y culturales; abarca paisajes, sitios históricos, entornos construidos, tradiciones pasadas y presentes y los conocimientos y experiencias vitales que se heredan. También registra y expresa procesos largos de la evolución histórica, constituyendo la esencia de muy diversas entidades nacionales, regionales, locales, indígenas y gran parte de la vida moderna (p.1).

En tal sentido, existe la concepción de patrimonio relacionado a prácticas culturales y la conservación de espacios ancestrales. Según autores como Troncoso y Almirón, (2005) "el patrimonio es una representación simbólica de una versión de la cultura e identidad, producto de un proceso social de selección definido por valores, demandas e intereses y con poder suficiente para lograrlo" (p.61).

En las comunidades los recursos existentes son parte del patrimonio de la colectividad, motivo de conservación para su permanencia. Al respecto Caraballo (2011) señala:

El patrimonio cultural y el patrimonio natural están cada vez más amenazados de destrucción, no sólo por las causas tradicionales de deterioro sino también por la evolución de la vida social y económica que las agrava con fenómenos de alteración o de destrucción aún más temibles (p.15).

Sin embargo, la necesidad de la población de generar cambios propicia la acción que afecta directamente al patrimonio, deteriorando la estabilidad del ecosistema natural especialmente en los espacios que forman parte de centros ceremoniales o sitios sagrados. Estas situaciones han generado algunos conflictos de los pueblos y nacionalidades indígenas con autoridades e instituciones en el territorio donde habitan. Ante este escenario, la UNESCO ha generado un proceso en marcha cuyo objetivo "es desarrollar una herramienta que permita reconocer, proteger, valorizar y nominar internacionalmente lugares de acuerdo a sus valores sagrados, y conformar con estos sitios de excelencia una red mundial" (UNESCO, 2017).

En la Declaración Universal de la Unesco sobre la Diversidad Cultural (2001) se proclama la diversidad cultural como patrimonio común de la humanidad. La Declaración promovió una nueva etapa histórica respecto a relevancia de la diversidad cultural... Condujo a la revisión de los modelos de cooperación internacional al integrar una dimensión cultural en la ejecución de estrategias y programas de desarrollo, propiciando así un reconocimiento cada vez mayor de la relación que existe entre la 
cultura y el desarrollo en los planos internacional y nacional. Aportó una concepción más completa y equilibrada desde el punto de vista geográfico de la diversidad cultural del mundo (UNESCO, 2001).

Núñez, Cóndor, y Loaiza (2003) afirman:

El tema de los "sitios sagrados" se encuentra en la agenda de discusión en diferentes instancias nacionales e internacionales pertinentes, vinculados a aspectos como su pertenencia al patrimonio cultural o natural de la humanidad, su papel en la conservación de la biodiversidad y reversión del deterioro ambiental, (...) La civilización actual tiende a ver a los lugares sagrados como restos de un pasado primitivo (p.1). Son puntos focales de comunicación y entendimiento con la Tierra, que permiten a los elegidos el convertirse en instrumentos entre las fuerzas de la naturaleza y los seres; a través de ceremonias y rituales para renovar sus energías (p.8).

Ecuador cuenta con once provincias en su zona norte, una de ella es Imbabura, conocida popularmente como la "Provincia de los Lagos"; por la presencia de grandes lagos que se encuentran dentro de su área, tales como el lago San Pablo y las lagunas de Cuicocha, Yahuarcocha ("Lago de Sangre") y Puruhanta en Pimampiro, lagunas de Piñán, lagunas de Mojanda y laguna Negra entre Sigsipamba y Monte.

Imbabura está localizada en la hoya del Chota. En la provincia sobresalen sus elevaciones; Imbabura (4.560 msnm), Cotacachi (4.944 msnm), Yanahurco de Piñán (4.535 msnm). Su población es de 329.755 habitantes con una extensión 4.611 km². Cuenta con recursos naturales y culturales que han logrado generar un elevado interés de conservación como patrimonio de los pueblos y nacionalidades que allí habitan. La existencia de los grupos étnicos, costumbres, tradiciones, conocimientos ancestrales, entre otros, ha conformado el valor cultural de las diferentes nacionalidades y etnias de esta provincia. La riqueza natural y cultural existente se debe también a la alta diversidad de prácticas culturales que se relacionan con el medio natural.

Otavalo, cantón de la provincia Imbabura, es considerado:

(...) el cuarto destino turístico a nivel nacional posee diversidad de lugares que han sido catalogados como patrimoniales conformándose como insignia del patrimonio indígena intangible de Ecuador donde se refleja un alto atractivo cultural y patrimonial; en tal sentido su diversidad juega un papel importante en el desarrollo turístico de la zona, por lo que su conservación exige una atención 
más priorizada por parte de las autoridades cantonales y provinciales, así como de sus habitantes (La Hora, 2019).

Otavalo alberga sitios especialmente sagrados. Según Córdoba (2005) "El sitio sagrado es un lugar de encuentro entre dos mundos diferentes que interactúan entre sí y que se legitiman el uno al otro de manera recíproca y constante" (p.278). Al respecto plantea Masaquiza (2017):

Pertenecen a las creencias del individuo (su propio lugar sagrado) o a las de una determinada comunidad, y en ambos casos debe ser aceptado y respetado por los demás, siempre que no vulnere los derechos del prójimo (como ha sucedido en otro tiempo en los lugares donde se practicaban sacrificios humanos). Una de las formas más destacadas de conservación basada en la cultura ha sido la identificación y protección de sitios sagrados, que con frecuencia albergan una valiosa biodiversidad, además de proteger ecosistemas con sus respectivas cosmovisiones y tradiciones (p.21).

Tal es el caso de la Cascada de Peguche, El Lechero, Laguna de Mojanda, Hatun Pukyo, entre otros. Los sitios sagrados o lugares sagrados llegan a ser un proceso de interiorización de creencias propias de cada individuo. Es decir, es la conexión de un pueblo con su mundo antiguo y su espiritualidad.

\section{REVISIÓN TEÓRICA}

Los sitios sagrados en las culturas indígenas. Iniciativas de su conservación.

La Conferencia de las Naciones Unidas sobre el Medio Ambiente y el Desarrollo (Cumbre de la Tierra), celebrada en el Brasil en 1992, fue un momento decisivo para la promoción de los derechos de los pueblos indígenas... declarándose un marco jurídico Internacional que reconoce la relación excepcional que los pueblos indígenas tienen con sus tierras tradicionales (Folleto, No. 10, 2019).

Según Servín (2013):

El sitio sagrado natural es como una escuela donde el indígena aprende, comunica, explica sueños, (...). Alrededor de los sitios sagrados se tejen creencias y realidades, zonas que sí son violentadas podrían generar la liberación de espíritus que enferman a los comuneros, alteran las condiciones 
normales cuando se ingresa en ellos, tales como lluvia intempestiva o un "neblinero" (p.5).

Estos espacios se vinculan a través del aprendizaje y la enseñanza de conocimientos de una generación a otra. La trasmisión y comunicación de lo aprendido permite la trascendencia de la importancia de estos lugares. Los sitios sagrados para los pueblos indígenas realmente es parte primordial en la naturaleza, puesto que el espacio físico y la creencia de las divinidades es fragmento de sus prácticas ancestrales; en tal sentido es necesario la conservación de dichos espacios. A tales efectos los países han propiciado iniciativas de conservación, para impedir la pérdida de los conocimientos y saberes ancestrales, que generaría el quebranto de la identidad de un pueblo.

Cabe mencionar que la diversidad natural está estrechamente ligada con la convivencia en armonía del hombre con su espacio, por tanto, para los pueblos indígenas constituye la base donde pueden manifestar libremente sus creencias culturales. Según Luque y Doode (2007):

La diversidad cultural es estrategia y reto de la sustentabilidad ambiental. Para los pueblos indígenas el desarrollo sustentable es una oportunidad para trascender su estado de pobreza al tiempo que conservan la base eco sistémica de la reproducción de su cultura (p.157).

Siendo así, las comunidades locales tienen un papel decisivo en la conservación de sitios sagrados, convirtiéndose este en un proceso objetivo de gran significación para la protección de la diversidad natural y cultural.

\section{MATERIALES Y MÉTODOS}

Las bases metodológicas de la investigación permiten obtener la información requerida. Para ello es necesario explicar determinadas técnicas o herramientas para asegurar la solidez de la investigación (Figura 1).

\section{Justificación del procedimiento.}

Las condiciones socio-económicas, culturales y ancestrales de las poblaciones indígenas del Ecuador y la provincia Imbabura, de acuerdo a su historia de coexistencia con la madre naturaleza, sus leyendas, ceremonias y cosmovisión han ido conformando un todo integral que hace ineludible conservar sitios ceremoniales identificados por los antepasados, que sirven de legado histórico cultural y que es 
necesario rescatar y potenciarlos en función de seguir conservando la cosmovisión indígena, trasmitiendo estas costumbres a generaciones futuras.

La naturaleza, los hábitos y el uso de las tradiciones del pueblo kichwa Otavalo son diferentes y se relacionan al contexto donde se desarrollan y viven otros grupos poblacionales del Ecuador. Cada grupo étnico del país tiene sus propias prácticas culturales, su propia manera de ver el mundo y de acuerdo a su cosmovisión, su propia manera de interpretar los fenómenos de la vida cotidiana; demostrando así la complejidad cultural existente en el país; es por ello que cualquier estrategia que se desee implementar para la conservación de un sitio sagrado, debe comenzar con un estudio sobre las prácticas culturales tradicionales de la comunidad y los potenciales sitios donde se llevan a cabo rituales ceremoniales, respaldado en las entrevistas a los líderes comunitarios y en los resultados de las encuestas aplicadas.

Figura 1. Matriz de información primaria.

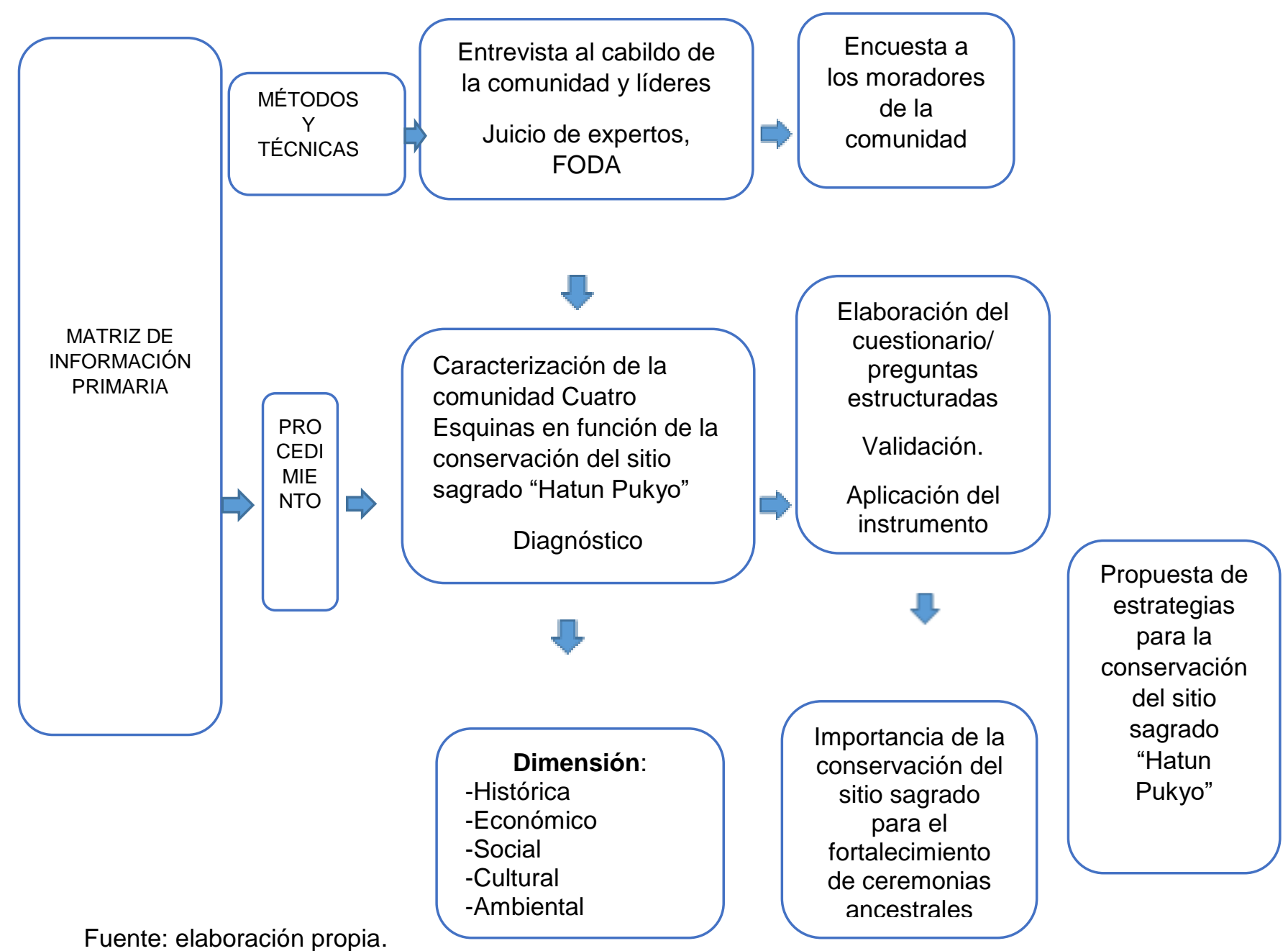


Las condiciones socio-económicas, culturales y ancestrales de las poblaciones indígenas del Ecuador y la provincia Imbabura, de acuerdo a su historia de coexistencia con la madre naturaleza, sus leyendas, ceremonias y cosmovisión han ido conformando un todo integral que hace ineludible conservar sitios ceremoniales identificados por los antepasados, que sirven de legado histórico cultural y que es necesario rescatar y potenciarlos en función de seguir conservando la cosmovisión indígena, trasmitiendo estas costumbres a generaciones futuras.

La naturaleza, los hábitos y el uso de las tradiciones del pueblo kichwa Otavalo son diferentes y se relacionan al contexto donde se desarrollan y viven otros grupos poblacionales del Ecuador. Cada grupo étnico del país tiene sus propias prácticas culturales, su propia manera de ver el mundo y de acuerdo a su cosmovisión, su propia manera de interpretar los fenómenos de la vida cotidiana; demostrando así la complejidad cultural existente en el país; es por ello que cualquier estrategia que se desee implementar para la conservación de un sitio sagrado, debe comenzar con un estudio sobre las prácticas culturales tradicionales de la comunidad y los potenciales sitios donde se llevan a cabo rituales ceremoniales, respaldado en las entrevistas a los líderes comunitarios y en los resultados de las encuestas aplicadas.

Cada comunidad posee su espacio territorial sagrado para sus propias prácticas ancestrales; por ende, el diagnóstico permite conocer la realidad de la comunidad en sus diferentes dimensiones, histórica, por cuanto es necesario conocer sus orígenes, ubicación geográfica, límites, líderes fundadores quienes dieron paso a la organización institucional de la comunidad y como se ha mantenido la integración y apoyo entre los moradores y la población total.

En cuanto a la dimensión económica, es necesario investigar el número de personas que se dedican a la actividad comercial, agrícola, artesanal, ganadera, entre otros, el tipo de servicio que brinda en la vertiente "Hatun Pukyo" y el manejo de los recursos económicos. En la dimensión social, la organización y coordinación del cabildo para realizar mingas comunitarias para la limpieza de las vertientes y otros fines relativos al sitio sagrado y su mantenimiento.

La descripción de la dimensión cultural, permite conocer las ceremonias ancestrales que se realizan en el sitio sagrado, como, el "Ñawi Mayllay" (lavado de cara) realizadas en matrimonios y bautizos. Además, la descripción del evento cultural y 
deportivo denominado "Sawarina Ñawi Mayllay Hatun Pukyo" realizado año tras año con el fin de fortalecer la identidad cultural de la comunidad y, por último, la dimensión ambiental para conocer la conservación del ecosistema.

Por cuanto se hace necesario conservar el sitio sagrado para ceremonias ancestrales en la comunidad Cuatro Esquinas, parroquia San Rafael de la Laguna. A su vez, el trabajo en conjunto de los moradores en el mantenimiento del lugar influye en el interés de valorar las riquezas que poseen.

Por tanto, es preciso coordinar las actividades en función de la conservación del sitio sagrado y propiciar su sostenibilidad; de modo que estimule la continuidad de las ceremonias ancestrales realizadas en este lugar y también a la recuperación de otras actividades que se han perdido. En tal sentido, el diseño abarca de forma íntegra procedimientos, técnicas e instrumentos para dar respuesta al objetivo trazado en la investigación.

\section{Bases metodológicas para la aplicación del procedimiento.}

Para la obtención de la información requerida se siguió el paradigma cualitativo y cuantitativo en la investigación. En el procedimiento cualitativo se utilizó la técnica de la entrevista mediante la guía de entrevista estructurada, abarcando todas las áreas de estudio. Esta técnica fue aplicada al cabildo y líderes de la comunidad que poseen experiencias y conocimientos acerca de los sitios sagrados, lo que permitió la caracterización de la comunidad Cuatro Esquinas en sus diferentes dimensiones, es decir, histórica, económica, social, cultural y ambiental, que consintió direccionar la definición de las estrategias. El procedimiento cuantitativo se basó en la utilización de la técnica de encuesta y su procesamiento.

La naturaleza, los hábitos y el uso de las tradiciones del pueblo kichwa Otavalo son diferentes y se relacionan al contexto donde se desarrollan y viven otros grupos poblacionales del Ecuador. Cada grupo étnico del país tiene sus propias prácticas culturales, su propia manera de ver el mundo y de acuerdo a su cosmovisión, su propia manera de interpretar los fenómenos de la vida cotidiana; demostrando así la complejidad cultural existente en el país; es por ello que cualquier estrategia que se desee implementar para la conservación de sitios sagrados, debe comenzar con un estudio sobre las prácticas culturales tradicionales de la comunidad y los potenciales 
sitios donde se llevan a cabo rituales ceremoniales, respaldado en las entrevistas a los líderes comunitarios y en los resultados de las encuestas aplicadas.

Los resultados del diagnóstico se detallan en tres etapas; en la primera etapa se caracteriza de forma integral a la comunidad Cuatro Esquinas, se realiza revisión de documentos, información general sobre tradiciones ancestrales en la comunidad, procesos de mantenimiento con los organismos implicados en el desarrollo de actividades ambientales, sociales y culturales relacionadas con el tema a investigar para determinar las insuficiencias que en el orden socio-cultural y ambiental inciden en la explotación racional y sostenible del sitio sagrado "Hatun Pukyo" y la celebración de prácticas ancestrales del "Ñawi Mayllay" en bautizos y matrimonios indígenas. Con esta fase se complementó la información interna y externa acorde a los fines esperados en la investigación.

En la segunda etapa se realizó la interpretación y análisis de los resultados más destacados de la aplicación de la encuesta, dirigida a un segmento poblacional de personas mayores de 16 años, por cuanto, en cada periodo administrativo el cabildo a petición de la misma población establece que personas de esa edad ya son capaces de integrarse y participar en los asuntos relacionadas al bienestar de la comunidad; además, poseen un criterio formado sobre la importancia y conservación constante del sitio sagrado objeto de estudio para la cultura kichwa Otavalo. Esta técnica se aplicó en una de las mingas realizadas en la comunidad y el resto en visitas a domicilios. Una de las ventajas fue abarcar casi todo el tamaño de la muestra en menos tiempo y los datos obtenidos posteriormente fueron tabulados para realizar los análisis correspondientes. El instrumento respectivo tuvo un contenido de veinte y dos preguntas de opción múltiple.

Es preciso obtener la confiabilidad del instrumento para que la investigación tenga los resultados esperados. La validación del instrumento se realizó mediante la técnica de juicio de expertos, (método Delphy) y la confiabilidad se ejecuta a partir del coeficiente estadístico Alfa de Cronbach, que es un índice de consistencia interna que toma valores entre 0 y 1 y sirve para comprobar si el instrumento recopila información defectuosa y por tanto llevaría a conclusiones equivocadas o si se trata de un instrumento fiable que hace mediciones estables. 
Conocida la magnitud de la población objeto de estudio (150 familias) es necesario la selección de la muestra. El diseño muestral se identifica por ser de tipo probabilístico, con un error de estimación de 0.09 , dando $n=67.96$

Se aplicó el instrumento de investigación a 68 jefes de hogar kichwas Otavalo. Entre ellos mujeres, hombres y jóvenes que ya cumplieron los 16 años de edad, lo que les posibilita la participación en las mingas comunitarias teniendo voz y voto en las decisiones a tomar. A criterio de los expertos y de los investigadores se tuvo en cuenta una permanencia estable de 3 a 5 años de los moradores de la comunidad.

\section{Aplicación de los instrumentos de investigación y análisis de resultados.}

Para desarrollar la técnica de la entrevista se realizó el mapeo de actores mediante la selección de los líderes de la comunidad, que permitió la esquematización y la sistematización de las diferentes dimensiones sujetas a análisis; es decir, la dimensión histórica, social, económica, cultural y ambiental de la comunidad y conocer el apoyo correspondiente a la iniciativa que se está realizando.

Se identifican 6 actores claves; ex-cabildos con más de 10 años de experiencia con la comunidad y también miembros que han tenido un amplio conocimiento del tema investigado, además se considera la participación del cabildo actual conformándose un número de 10 personas, lo que permitió la obtención de la información para una mejor comprensión y fluidez de la pesquisa con los entrevistados.

La sistematización de la información permitió lograr definir acciones específicas que ayuden a garantizar el mayor y mejor apoyo para la propuesta de estrategias para la conservación del sitio sagrado "Hatun Pukyo" en la comunidad Cuatro Esquinas.

Los resultados obtenidos en este proceso están relacionados con:

- Descripción histórica de constitución de la comunidad y formas iniciales de organización en la comunidad.

- Análisis económico-social de la actividad laboral, el manejo de recursos económicos para ámbitos de conservación del sitio sagrado.

- Descripción de los eventos realizados como fortalecimiento de tradiciones culturales en el sitio sagrado "Hatun Pukyo". 
- Describir acciones que se han tomado para el mantenimiento del sitio sagrado "Hatun Pukyo".

Los expertos (5) fueron seleccionados utilizando el método Delphi, en función del objetivo prefijado-y atendiendo a criterios de experiencia, posición, responsabilidad, acceso a la información y disponibilidad de participación. Se elaboró la matriz FODA, con el objetivo de identificar el cuadrante en el cual se encuentra la zona objeto de estudio, para de esta forma sintetizar la información relevante, que permita consolidar la propuesta de estrategias para la conservación del sitio sagrado "Hatun Pukyo" en la comunidad Cuatro Esquinas.

La codificación y el respectivo procesamiento de la encuesta se realizó mediante la utilización del software Statistical Package for the Social Sciences (SPSS) versión 24 para Windows. A continuación, se detallan los resultados de la encuesta aplicada a las familias objeto de estudio en función a la importancia de la conservación del sitio sagrado "Hatun Pukyo". La interpretación y análisis de los resultados se engloba desde la pregunta 1 hasta la pregunta 19 con los porcentajes de mayor relevancia (Figura 2).

Figura 1. Resultados de los ítems 1-19.

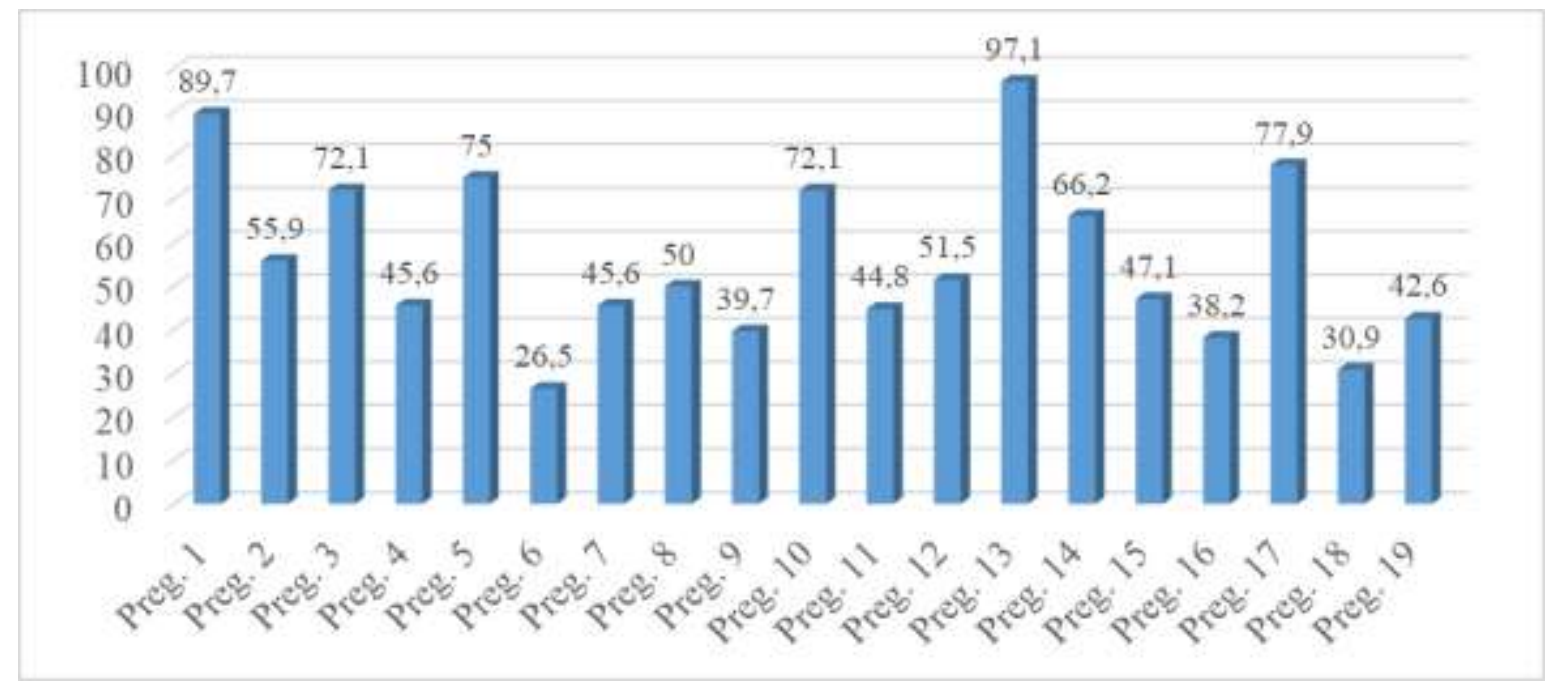

Fuente: elaboración propia (2018). 


\section{Análisis}

En la pregunta 2, De acuerdo a su cosmovisión andina, ¿cómo considera usted los sitios sagrados de su comunidad?, el mayor porcentaje recae en la opción importante dando como resultado que para los moradores de la comunidad Cuatro Esquinas el sitio sagrado como la vertiente es sumamente importante.

Tabla 1. Resumen del caso, ítem 2.

\begin{tabular}{|l|l|r|}
\hline \multicolumn{3}{|l|}{ Resumen de caso } \\
\hline \multirow{2}{*}{$N^{\circ}$} & Válido & 68 \\
\cline { 2 - 3 } & Perdidos & 0 \\
\hline
\end{tabular}

Fuente: Programa SPSS, versión 24.

Tabla .1.1. Distribución de los datos con relación a la pregunta 2.

\begin{tabular}{|l|r|r|r|}
\hline \multicolumn{4}{|c|}{$\begin{array}{c}\text { Pregunta 2. De acuerdo a su cosmovisión andina, ¿cómo considera usted } \\
\text { los sitios sagrados de su comunidad? }\end{array}$} \\
\hline & Frecuencia & Porcentaje \% & Porcentaje acumulado \% \\
\hline Nada importante & 4 & 5,9 & 5,9 \\
\hline Poco importante & 4 & 5,9 & 11,8 \\
\hline Indiferente & 2 & 2,9 & 14,7 \\
\hline Importante & 38 & 55,9 & 70,6 \\
\hline Muy importante & 20 & 29,4 & 100,0 \\
\hline Total & 68 & 100,0 & \\
\hline
\end{tabular}

Fuente: Programa SPSS, versión 24.

Figura 3. Consideración de los sitios sagrados de la comunidad desde la cosmovisión andina.

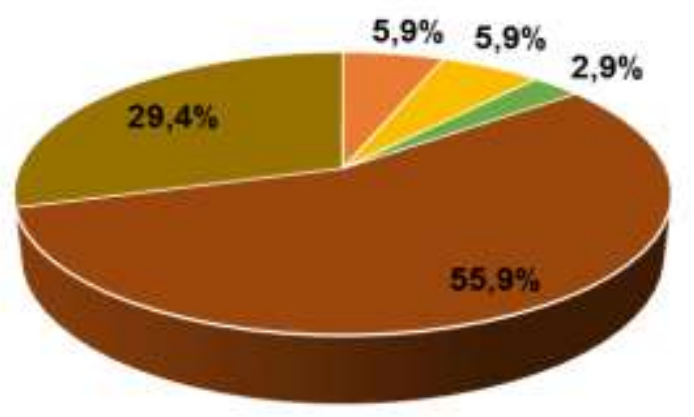

$$
\begin{aligned}
& \text { - Nada importante } \\
& \text { - Poco importante } \\
& \text { - Indiferente } \\
& \text { = Importante } \\
& \text { - Muy importante }
\end{aligned}
$$

Fuente: elaboración propia a partir de la Investigación de campo (mayo 2018). 


\section{Análisis}

En la pregunta 7 de la investigación ¿Cuándo usted ha visitado el sitio sagrado "Hatun Pukyo" ha observado algún tipo de anuncio/s relacionado/s con la conservación? Dentro de las opciones de respuesta el mayor porcentaje se refleja en la opción muy pocas veces. Esto quiere decir que en el sitio sagrado de la comunidad es necesario impulsar medidas de mantenimiento para su conservación, pues muy pocas veces los visitantes han observado algún tipo de anuncio/os.

Tabla 2. Resumen de caso, ítem 7.

\begin{tabular}{|l|l|r|}
\hline \multicolumn{3}{|l|}{ Resumen de caso } \\
\hline \multirow{2}{*}{$N^{\circ}$} & Válido & 68 \\
\cline { 2 - 3 } & Perdidos & 0 \\
\hline
\end{tabular}

Fuente: Programa SPSS, versión 24.

Tabla 2.2. Distribución de los datos con relación a la pregunta 7 .

\begin{tabular}{|l|r|r|r|}
\hline \multicolumn{4}{|c|}{$\begin{array}{c}\text { Pregunta 7. ¿Cuándo usted ha visitado el sitio sagrado “Hatun } \\
\text { Pugyo" ha observado algún tipo de anuncio/s relacionado/s con la } \\
\text { conservación? }\end{array}$} \\
\hline & Frecuencia & Porcentaje \% & Porcentaje acumulado \% \\
\hline Nunca & 5 & 7,4 & 7,4 \\
\hline Muy pocas veces & 31 & 45,6 & 52,9 \\
\hline Algunas veces & 11 & 16,2 & 69,1 \\
\hline Casi siempre & 8 & 11,8 & 80,9 \\
\hline Siempre & 13 & 19,1 & 100,0 \\
\hline Total & 68 & 100,0 & \\
\hline
\end{tabular}

Fuente: Programa SPSS, versión 24. 
Figura 4. Algún tipo de anuncio/s relacionado/s observado en el sitio sagrado "Hatun Pukyo".

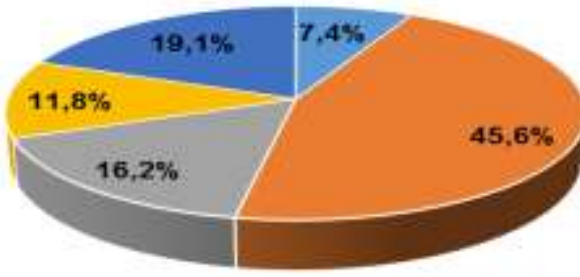

- Nunca

- Muy pocas veces

- Algunas veces

- Casi siempre

- Siempre

Fuente: elaboración propia a partir de la Investigación de campo (mayo 2018).

\section{Análisis}

Siguiendo con el análisis en la pregunta 11 ¿Qué problema ha observado durante estos últimos tres años en relación al sitio sagrado "Hatun Pukyo" de su comunidad?

Tabla 3. Resumen de caso, respuesta múltiple, ítem 11

\begin{tabular}{|c|c|c|c|c|c|c|}
\hline \multirow[b]{3}{*}{ Pregunta } & \multicolumn{6}{|c|}{ Resumen de caso } \\
\hline & \multicolumn{2}{|r|}{ Válidos } & \multicolumn{2}{|r|}{ Perdidos } & \multicolumn{2}{|r|}{ Total } \\
\hline & $\mathrm{N}$ & Porcentaje & $\mathrm{N}$ & Porcentaje & $\mathrm{N}$ & Porcentaje \\
\hline & 67 & $98,5 \%$ & 1 & $1,5 \%$ & 68 & $100,0 \%$ \\
\hline
\end{tabular}

Fuente: Programa SPSS, versión 24.

Tabla 3.1. Distribución de los datos con relación a la pregunta 11.

Pregunta 11. ¿Qué problema ha observado durante estos últimos tres años en relación al sitio sagrado "Hatun Pugyo" de su comunidad?

\begin{tabular}{|l|r|r|r|}
\hline & \multicolumn{2}{|c|}{ Respuestas } & Porcentaje \\
\cline { 2 - 3 } & $\mathrm{N}$ & Porcentaje & de casos \\
\hline Disminución de áreas verdes & 9 & $11,0 \%$ & $13,4 \%$ \\
\hline Basuras alrededor & 30 & $36,6 \%$ & $44,8 \%$ \\
\hline Contaminación por el servicio & 11 & $13,4 \%$ & $16,4 \%$ \\
\hline Disminución del caudal de agua & 28 & $34,1 \%$ & $41,8 \%$ \\
\hline Ninguna & 3 & $3,7 \%$ & $4,5 \%$ \\
\hline Otros & 1 & $1,2 \%$ & $1,5 \%$ \\
\hline Total & 82 & $100,0 \%$ & $122,4 \%$ \\
\hline a. Grupo de dicotomía tabulado en el valor 1. \\
\hline
\end{tabular}

Fuente: Programa SPSS, versión 24. 
Figura 5. Tipo de problemas en el sitio sagrado "Hatun Pukyo" en los últimos tres años.
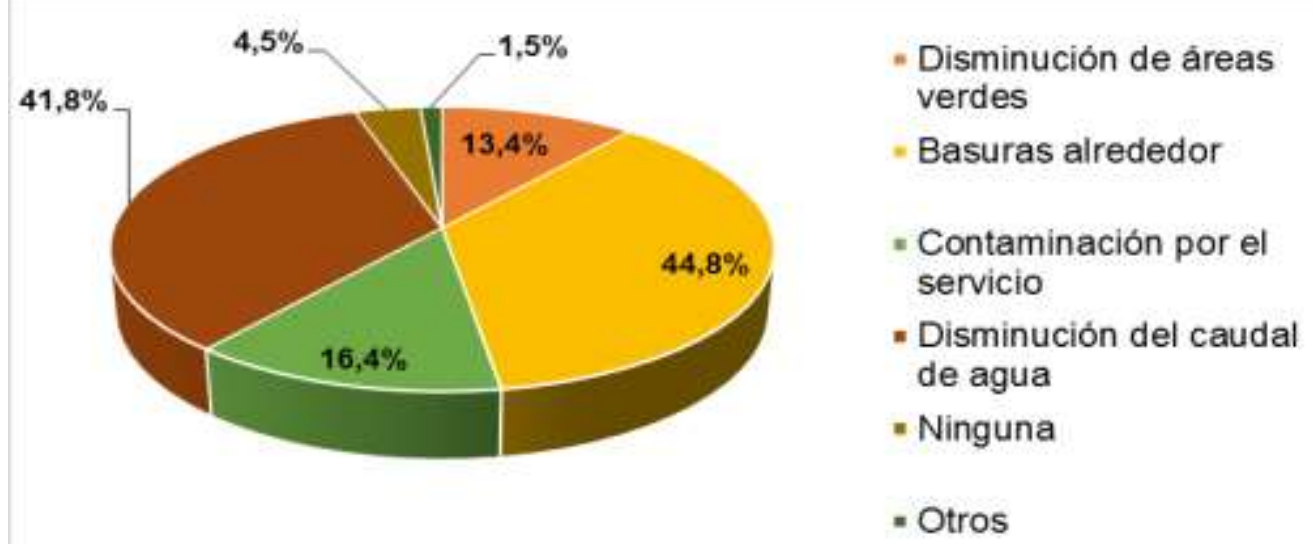

Fuente: elaboración propia a partir de la Investigación de campo (mayo 2018).

\section{Análisis}

El mayor porcentaje recae en la existencia de cantidades de desechos sólidos en el área del sitio y la disminución del caudal de agua; este resultado da a conocer que el sitio sagrado requiere de acciones conjuntas de moradores de la comunidad donde se asienta, así como también de las comunidades aledañas por cuanto el lugar es utilizado por varias comunidades.

En la pregunta 14. ¿Con qué frecuencia se realizan las ceremonias ancestrales en el sitio sagrado "Hatun Pukyo" de su comunidad?

Tabla 4. Resumen de caso, ítem 14.

\begin{tabular}{|l|l|r|}
\hline \multicolumn{2}{|l|}{ Resumen de caso } \\
\hline \multirow{2}{*}{$N^{\circ}$} & Válido & 68 \\
\cline { 2 - 3 } & Perdidos & 0 \\
\hline \multicolumn{2}{|l|}{ Media } & 2,13 \\
\hline \multicolumn{2}{|l|}{ Mediana } & 2,00 \\
\hline
\end{tabular}

Fuente: Programa SPSS, versión 24.

Tabla 1. Distribución de datos con relación a la pregunta 14.

\begin{tabular}{|l|r|r|r|}
\hline \multicolumn{3}{|c|}{$\begin{array}{c}\text { Pregunta } \mathbf{1 4} \text { ¿Con qué frecuencia se realizan las ceremonias } \\
\text { ancestrales en el sitio sagrado “Hatun Pugyo” de su comunidad? }\end{array}$} \\
\hline & Frecuencia & Porcentaje \% & Porcentaje acumulado \% \\
\hline Semanal & 7 & 10,3 & 10,3 \\
\hline Mensual & 45 & 66,2 & 76,5 \\
\hline
\end{tabular}




\begin{tabular}{|l|r|r|r|}
\hline Anual & 16 & 23,5 & 100,0 \\
\hline Total & 68 & 100,0 & \\
\hline
\end{tabular}

Fuente: Programa SPSS, versión 24.

Figura 6. Frecuencia de ceremonias ancestrales en el sitio sagrado "Hatun Pukyo".

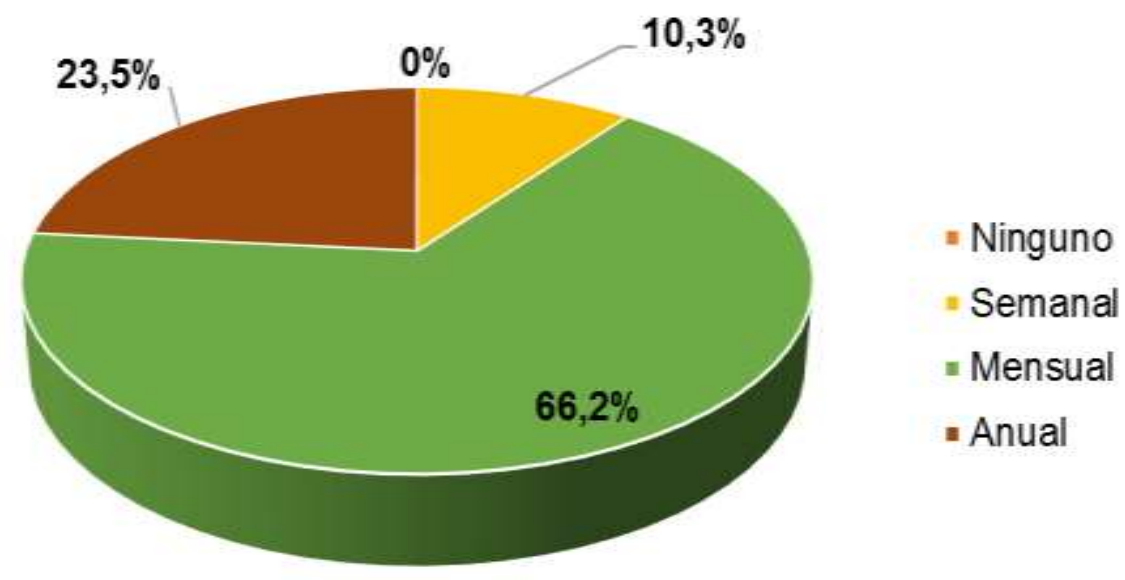

Fuente: elaboración propia a partir de la Investigación de campo (mayo 2018).

\section{Análisis}

El tipo de ceremonias ancestrales más visto en el lugar es el "Ñawi Mayllay" y la frecuencia según las opciones presentadas es cada mes, demostrándose a través de los resultados de la pregunta 15 la trascendencia tan significativa de estas ceremonias, que parte de la identidad de la población, del sentido de pertenencia que tiene cada uno de ellos dentro de las prácticas culturales de la comunidad.

En la pregunta 19. ¿Cómo considera la gestión de los líderes comunitarios en el área de desarrollo comunitario para la conservación del sitio sagrado "Hatun Pukyo"?

Tabla 5. Resumen de caso, ítem 19.

\begin{tabular}{|l|l|r|}
\hline \multicolumn{2}{|l|}{ Resumen de caso } \\
\hline \multirow{2}{*}{$N^{\circ}$} & Válido & 68 \\
\cline { 2 - 3 } & Perdidos & 0 \\
\hline
\end{tabular}

Fuente: Programa SPSS, versión 24.

Tabla 5.1. Distribución de datos con relación a la pregunta 19. 


\begin{tabular}{|l|r|r|r|}
\hline \multicolumn{3}{|c|}{$\begin{array}{c}\text { Pregunta } 19 \text { ¿Cómo considera la gestión de los líderes comunitarios } \\
\text { en el área de desarrollo comunitario para la conservación del sitio } \\
\text { sagrado “Hatun Pukyo”? }\end{array}$} \\
\hline & Frecuencia & Porcentaje \% & Porcentaje acumulado \% \\
\hline Muy insuficiente & 1 & 1,5 & 1,5 \\
\hline Insuficiente & 9 & 13,2 & 14,7 \\
\hline Regular & 29 & 42,6 & 57,4 \\
\hline Buena & 15 & 22,1 & 79,4 \\
\hline Muy buena & 10 & 14,7 & 94,1 \\
\hline Excelente & 4 & 5,9 & 100,0 \\
\hline & 68 & 100,0 & \\
\hline
\end{tabular}

Fuente: Programa SPSS, versión 24.

Figura 7. Gestión de los líderes comunitarios.

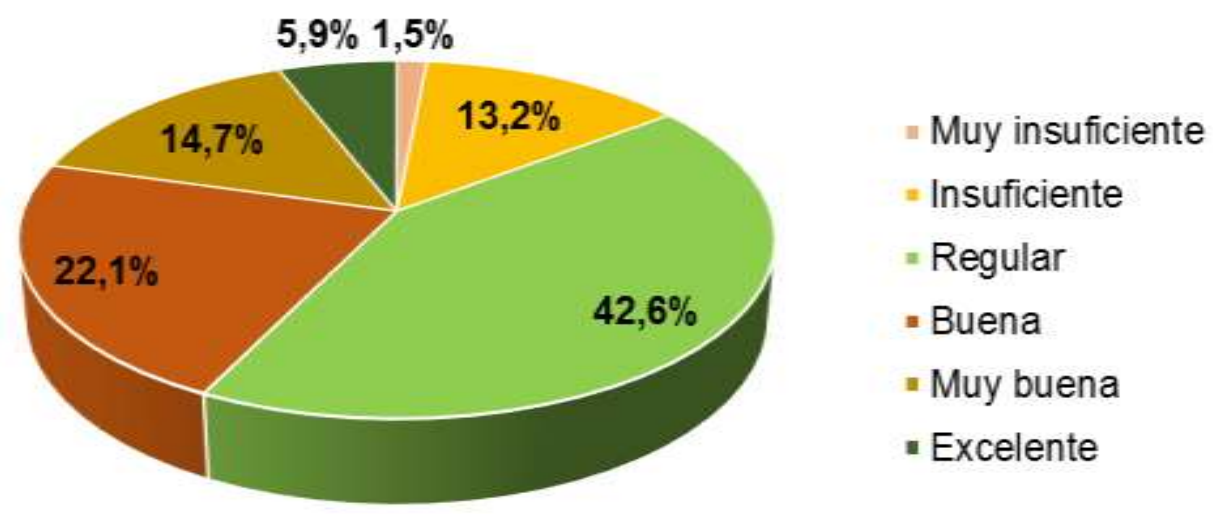

Fuente: elaboración propia a partir de la Investigación de campo (mayo 2018).

\section{Análisis}

El 42.6\% de las personas considera que la gestión de los líderes especialmente en la conservación del lugar ha sido regular. Este resultado da a conocer que el cabildo anual tiene una debilidad en los procesos de gestión y planificación para el fortalecimiento de las mingas comunitarias como una acción pertinente para la conservación del sitio sagrado.

La pregunta 20 ¿Qué recursos de información hacen falta para promover la protección-conservación del sitio sagrado "Hatun Pukyo" en su comunidad? 
Tabla 2. Resumen de caso, respuesta múltiple, ítem 20.

\begin{tabular}{|c|c|c|c|c|c|}
\hline \multicolumn{6}{|c|}{ Resumen de caso } \\
\hline \multicolumn{2}{|c|}{ Válidos } & \multicolumn{2}{|c|}{ Perdidos } & \multicolumn{2}{|c|}{ Total } \\
\hline $\mathrm{N}^{\circ}$ & Porcentaje & $\mathrm{N}$ & Porcentaje & $\mathrm{N}$ & Porcentaje \\
\hline 68 & $100,0 \%$ & 0 & $0,0 \%$ & 68 & $100,0 \%$ \\
\hline
\end{tabular}

Fuente: Programa SPSS, versión 24.

Tabla 6.1. Distribución de datos con relación a la pregunta 20.

\begin{tabular}{|c|c|c|c|}
\hline \multicolumn{4}{|c|}{$\begin{array}{l}\text { Pregunta 20. ¿Qué recursos de información hacen falta para promover } \\
\text { la protección-conservación del sitio sagrado "Hatun Pukyo" en su } \\
\text { comunidad? }\end{array}$} \\
\hline & \multicolumn{2}{|c|}{ Respuestas } & \multirow{2}{*}{$\begin{array}{l}\text { Porcentaje de } \\
\text { casos }\end{array}$} \\
\hline & $\mathrm{N}$ & Porcentaje & \\
\hline Rótulo & 26 & $28,0 \%$ & $38,2 \%$ \\
\hline Señalética & 33 & $35,5 \%$ & $48,5 \%$ \\
\hline Anuncios & 7 & $7,5 \%$ & $10,3 \%$ \\
\hline Capacitación & 26 & $28,0 \%$ & $38,2 \%$ \\
\hline Otros & 1 & $1,1 \%$ & $1,5 \%$ \\
\hline Total & 93 & $100,0 \%$ & $136,8 \%$ \\
\hline
\end{tabular}

Fuente: elaboración propia a partir de la Investigación de campo (mayo 2018).

Figura 8: Recursos de información que hacen falta en el sitio sagrado "Hatun Pukyo".

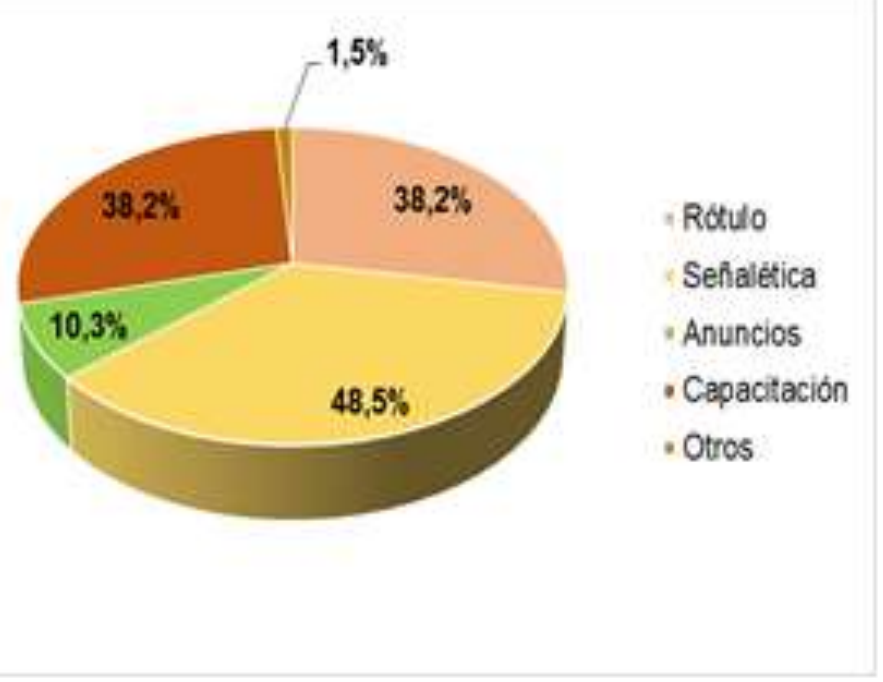

Fuente: elaboración propia a partir de la Investigación de campo (mayo 2018).

\section{Análisis}

Según los resultados el $48.5 \%$ de las personas considera que en el sitio sagrado "Hatun Pukyo" le hace falta recursos de información como señaléticas, ya que, en el 
lugar según la observación de campo y sus resultados, existe poca información acerca de la conservación del sitio; por lo que la opción de rótulos como recurso de información se constituye en base para generar procesos de mantenimiento y conservación.

En la pregunta 21. ¿Qué acciones se deberán llevar a cabo para solucionar los problemas relacionados con la conservación del sitio sagrado "Hatun Pukyo" de su comunidad?, se obtuvieron los siguientes resultados.

Tabla 7. Resumen de caso, respuesta múltiple, ítem 21.

\begin{tabular}{|r|r|r|r|r|r|}
\hline \multicolumn{7}{|c|}{ Resumen de caso } \\
\hline \multicolumn{2}{|c|}{ Válidos } & \multicolumn{2}{|c|}{ Perdidos } & \multicolumn{2}{c|}{ Total } \\
\hline$N^{\circ}$ & Porcentaje & \multicolumn{1}{|c|}{$\mathrm{N}^{\circ}$} & Porcentaje & $\mathrm{N}$ & Porcentaje \\
\hline 68 & $100,0 \%$ & 0 & $0,0 \%$ & 68 & $100,0 \%$ \\
\hline
\end{tabular}

Fuente: Programa SPSS, versión 24.

Tabla 7.1. Distribución de datos con relación a la pregunta 21.

\begin{tabular}{|c|c|c|c|}
\hline \multicolumn{4}{|c|}{$\begin{array}{l}\text { Pregunta 21. ¿Qué acciones se deberán II } \\
\text { los problemas relacionados con la conse } \\
\text { “Hatun Pukyo” de su comunidad? }\end{array}$} \\
\hline & \multicolumn{2}{|c|}{ Respuestas } & \multirow[b]{2}{*}{ Porcentaje de casos } \\
\hline & $\mathrm{N}$ & Porcentaje & \\
\hline Seguimiento & 30 & $36,1 \%$ & $44,1 \%$ \\
\hline Implementación & 8 & $9,6 \%$ & $11,8 \%$ \\
\hline Formación & 16 & $19,3 \%$ & $23,5 \%$ \\
\hline Planificación & 27 & $32,5 \%$ & $39,7 \%$ \\
\hline Otros & 2 & $2,4 \%$ & $2,9 \%$ \\
\hline Total & 83 & $100,0 \%$ & $122,1 \%$ \\
\hline
\end{tabular}

Fuente: Programa SPSS, versión 24. 
Figura 9: Acciones de solución relacionados con la conservación del sitio sagrado "Hatun Pukyo"

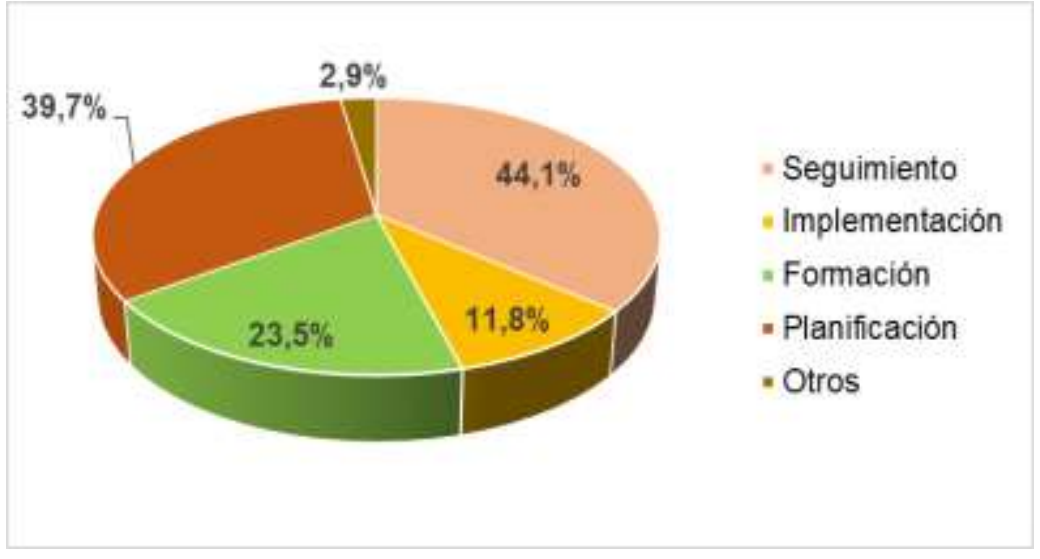

Fuente: Elaboración propia a partir de la Investigación de campo (mayo 2018).

\section{Análisis}

Dentro de las acciones para la conservación del sitio sagrado las personas consideran que es necesario la planificación, seguimiento y control de las mingas comunitarias en el sitio sagrado para su mantenimiento, lo que ratifica que unas de las acciones principales es la planificación mensual de mingas comunitarias enfocándose en la implementación de materiales para su mantenimiento y su respectivo seguimiento para obtener los resultados esperados.

En la pregunta 21. ¿Con cuáles de las siguientes declaraciones está de acuerdo con que se obtengan los siguientes resultados? (figura 5).

Figura 10. Declaraciones de las opciones.

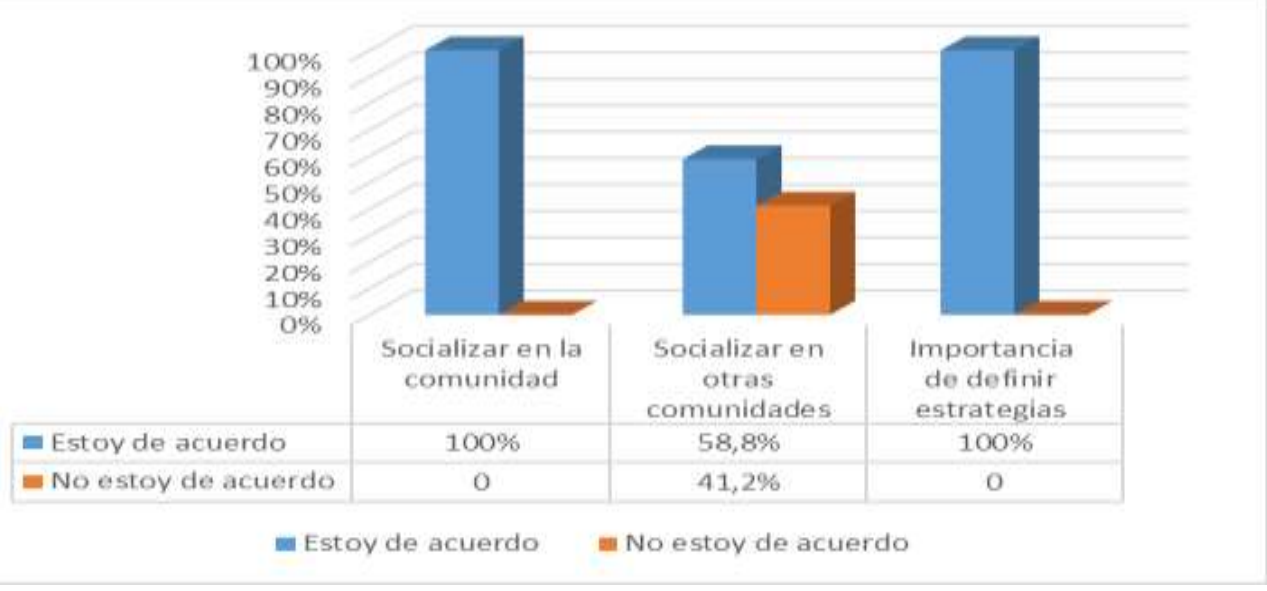

Fuente: elaboración propia a partir de la Investigación de campo (mayo 2018). 
El $100 \%$ de los encuestados consideran que es significativo dar a conocer a los moradores de la comunidad la importancia de la conservación del sitio sagrado "Hatun Pukyo", además están en total acuerdo con la definición de estrategias de conservación del lugar.

2.3. Propuesta de estrategia para la conservación del sitio sagrado "Hatun Pukyo" en la comunidad Cuatro Esquinas.

En la actualidad la comunidad lleva un proceso de cambios en función de la conservación del sitio sagrado, proceso que ha tenido una alta consideración por parte de las autoridades y moradores de la comunidad. De acuerdo a los saberes ancestrales del pueblo kichwa Otavalo, expresan el cuestionamiento de cómo seguir fortaleciendo las prácticas ancestrales realizadas en el sitio y conocer la manera de recuperar la esencia de fomentar su mantenimiento. Por tanto, como aporte de la investigación a continuación se presenta el resumen de la propuesta (Tabla 8). 
Tabla 8. Matriz de propuesta de estrategias para la conservación del sitio sagrado "Hatun Pukyo".

\begin{tabular}{|c|c|c|c|c|c|c|c|}
\hline Objetivo general & $\begin{array}{l}\text { Contribuir a la cor } \\
\text { sagrado "Hatun } \mathrm{Pl}\end{array}$ & $\begin{array}{l}\text { nunidad Cuatro Esquinas en e } \\
\text { ıyo" que permita la realizaciór }\end{array}$ & $\begin{array}{l}\text { año } 2018 \text { con } ~ \\
\text { | de ceremonias }\end{array}$ & $\begin{array}{l}\text { Ina propuesta de esi } \\
\text { ancestrales. }\end{array}$ & ategias par & a la conser & ación del sitio \\
\hline \multirow[t]{2}{*}{ Objetivos } & \multirow[t]{2}{*}{ Estrategias } & \multirow[t]{2}{*}{ Actividades } & \multirow[t]{2}{*}{ Participantes } & \multirow[t]{2}{*}{ Responsables } & \multicolumn{2}{|c|}{ Periodo de ejecución } & \multirow[t]{2}{*}{ Presupuesto } \\
\hline & & & & & F/l & $F / F$ & \\
\hline $\begin{array}{lr}\text { Definir } & \text { los } \\
\text { recursos } & \text { de } \\
\text { información } & \\
\text { relacionados a } & \text { la } \\
\text { protección } & \text { y } \\
\text { conservación } & \text { del } \\
\text { sitio sagrado } \\
\text { "Hatun Pukyo" }\end{array}$ & $\begin{array}{l}\text { Implementar los } \\
\text { recursos de } \\
\text { información en toda } \\
\text { el área del sitio } \\
\text { sagrado que } \\
\text { contribuyan en la } \\
\text { corresponsabilidad }\end{array}$ & $\begin{array}{l}\text { _Identificar señaléticas acordes a } \\
\text { la protección y conservación } \\
\text { _Establecer un logo del sitio } \\
\text { sagrado } \\
\text { _Implantar los rótulos en las } \\
\text { entradas } \\
\text { _Arreglar fachada de las paredes } \\
\text { _Gestionar tachos de basura } \\
\text { _Coordinar con el cabildo para la } \\
\text { implementación de los recursos } \\
\text { informativos }\end{array}$ & $\begin{array}{l}\text { _Cabildo de la } \\
\text { comunidad } \\
\text { _Líderes } \\
\text { _Jóvenes } \\
\text { _Moradores }\end{array}$ & $\begin{array}{l}\text { _Administración } \\
\text { anual de la } \\
\text { comunidad Cuatro } \\
\text { Esquinas } \\
\text { _Gobierno Autónomo } \\
\text { Descentralizado de } \\
\begin{array}{l}\text { San Rafael de la } \\
\text { Laguna } \\
\text { _Presidente de la } \\
\text { comunidad }\end{array}\end{array}$ & $30 / 8 / 2018$ & $30 / 9 / 2018$ & $\$ 700.00$ \\
\hline $\begin{array}{l}\text { Programar } \\
\text { actividades } \\
\text { comunitarias en } \\
\text { función de la } \\
\text { conservación del } \\
\text { sitio sagrado } \\
\text { "Hatun Pukyo" }\end{array}$ & $\begin{array}{l}\text { Planificar de forma } \\
\text { mensual las mingas } \\
\text { comunitarias }\end{array}$ & $\begin{array}{l}\text { _Recopilar la información a través } \\
\text { de un cuestionario que permita } \\
\text { conocer el día de la semana } \\
\text { acorde para asistir a la minga } \\
\text { _Elaborar el cronograma de las } \\
\text { actividades mensuales } \\
\text { _Elaborar una matriz de }\end{array}$ & $\begin{array}{l}\text { _Jóvenes } \\
\text { _Líderes } \\
\text { comunitarios }\end{array}$ & $\begin{array}{l}\text { _Cabildo de la } \\
\text { comunidad } \\
\text { Estudiantes de la }\end{array}$ & 29/9/2018 & $15 / 10 / 2018$ & $\$ 200.00$ \\
\hline
\end{tabular}

ISSN: 1390-9320, Vol. 6, No. 4, agosto 2019 


\begin{tabular}{|c|c|c|c|c|c|c|c|}
\hline & & $\begin{array}{l}\text { seguimiento y control de las } \\
\text { mingas } \\
\text { _Implementación de utensilios } \\
\text { para el mantenimiento del sitio } \\
\text { sagrado } \\
\text { _Socializar al cabildo }\end{array}$ & _Cabildo & educación superior & & & \\
\hline $\begin{array}{l}\text { Socializar la } \\
\text { propuesta a los } \\
\text { miembros de la } \\
\text { comunidad } \\
\text { Cuatro Esquinas } \\
\text { parroquia de } \\
\text { San Rafael de la } \\
\text { Laguna }\end{array}$ & $\begin{array}{l}\text { Convocar a los } \\
\text { moradores de la } \\
\text { comunidad }\end{array}$ & $\begin{array}{l}\text { _Anuncios por el alto parlante } \\
\text { _Elaboración del orden del día } \\
\text { _Exposición de la propuesta }\end{array}$ & $\begin{array}{l}\text { Cabildo } \\
\text { Moradores de } \\
\text { la comunidad }\end{array}$ & $\begin{array}{l}\text { Elsa Cachimuel } \\
\text { Lidia Díaz }\end{array}$ & $9 / 11 / 2018$ & 9/11/2018 & $\$ 50,00$ \\
\hline
\end{tabular}

Fuente: elaboración propia (2018). 
Las estrategias en esta propuesta estan sujetas a los resultados obtenidos en el campo real de estudio. Las acciones establecidas son definidas y direccionadas a la mejora. En esta investigacion se realizaron tres estrategias con su respectivo objetivo que se detallan a continuación.

\section{Estrategia 1: Recursos de información}

Los recursos de información nacen de la necesidad real de la investigación realizada, por cuanto existe un alto porcentaje de personas que indicaron que el sitio sagrado "Hatun Pukyo" no han observado ningún tipo de anuncio/s relacionado/s con la conservación del lugar. Los recursos de información permitirán que las personas quienes hacen uso o visitan el lugar se informe de la importancia de conservar los recursos naturales existentes en el lugar.

En relación al patrimonio cultural de la comunidad, es imprescindible realizar eventos relacionados para el fortalecimiento de las prácticas culturales vivas del pueblo kichwa Otavalo.

\section{Objetivo específico 1}

Definir los recursos de información relacionados a la protección y conservación del sitio sagrado "Hatun Pukyo"

De acuerdo a la observación del área y los resultados de la aplicación de la encuesta se puede decir que en el lugar no existen recursos información, especialmente de señaléticas que visualicen los visitantes para así tener una corresponsabilidad de las acciones de conservación. La implementación de rótulos y señaléticas en toda el área y la capacitación de la importancia que representa la riqueza cultural y natural que poseen, pretende la sensibilización de las personas quiénes hacen uso o visitan el sitio sagrado "Hatun Pukyo".

La señalización del área es un aspecto fundamental para las organizaciones principalmente si en el lugar brindan un servicio. Este aspecto es una medida útil para advertir, un peligro, reforzar o recordar las normas de comportamiento que deben llevar al visitar o hacer uso del sitio. La finalidad de la implementación señalética es atraer la atención de quién la observa, dar a conocer el mensaje previsto, informar 
sobre la conducta que deben seguir y permitir a quién le observe crear la necesidad de cumplir con lo establecido.

Para la implementación de las señaléticas se debe tomar en cuenta aspectos de ubicación, ya que de nada serviría colocar en un lugar donde no puedan observar. Y por último después de la ejecución llevar un proceso de mantenimiento del buen estado de las señales.

\section{Estrategia 2. Planificación mensual de las mingas comunitarias}

La planificación mensual de las mingas comunitarias surge del resultado de la aplicación de la encuesta a la población objeto de estudio. La planificación es una herramienta básica para cualquier empresa, institución, organización, comunidad, entre otros. Esto permite la gestión y toma de decisiones entorno al quehacer actual mejorando lo que se realizó anteriormente y lo que deben cambiar a futuro para la correcta efectividad de las acciones.

Esta planificación mensual de las mingas consiste en la formulación de secuencial de las actividades de mantenimiento que deben llevar especialmente del sitio sagrado "Hatun Pukyo" y el área que conforma la comunidad. La planificación mensual debe estar sujeta a los objetivos de carácter prioritario.

\section{Objetivo específico 2}

\section{Programar actividades comunitarias en función de la conservación del sitio sagrado "Hatun Pukyo".}

La recopilación de la información para conocer el día de asistencia a la minga comunitaria se realizará mediante la aplicación de un cuestionario que permita el establecer las fechas y el horario. La conservación del sitio sagrado y otros espacios de encuentro común mediante un plan de actividades es de gran importancia, ya que contribuye a identificar el objetivo de la minga comunitaria, los responsables y el tiempo.

El beneficio de un plan de actividades es focalizar las tareas orientadas al cumplimiento del objetivo propuesto, mejor el seguimiento y control de las actividades que se realiza en el sitio sagrado y el mantenimiento de calles de la comunidad, 
aumentar el nivel de compromiso por parte del cabildo y los moradores y optimiza los recursos a utilizar.

Tabla 9. Plan de actividades

PLAN DE ACTIVIDADAD MENSUAL DE MANTENIMIENTO DE LA COMUNIDAD CUATRO ESQUINAS

\begin{tabular}{|c|c|c|c|c|}
\hline $\mathrm{N}^{\circ}$ & Acciones & Responsables & Participantes & Periodo \\
\hline 1 & Limpieza de las vertientes & Presidente/a & Moradores & Permanente \\
\hline 2 & Corte de malezas por las calles & Vicepresidente/a & Moradores & Mensual \\
\hline 3 & $\begin{array}{l}\text { Limpieza de la casa comuninal } \\
\text { y estadio }\end{array}$ & Secretario/a & Moradores & Mensual \\
\hline 4 & $\begin{array}{l}\text { Arreglo de los baches en las } \\
\text { calles }\end{array}$ & Tesorero/a & Moradores & Mensual \\
\hline 5 & Convocatoria & Sindico & Sindico & Permanente \\
\hline
\end{tabular}

Fuente: elaboración propia (2018).

Estrategia 3. Convocar a los moradores de la comunidad para dar a conocer las estrategias.

Considerando la relación que existente entre los moradores de la comunidad y el cabildo y conociendo el interés por parte de los involucrados, se procederá a dar a conocer la propuesta a las autoridades y miembros de la comunidad Cuatro Esquinas para obtener su aprobación y realizar su entrega para que se considere y evalué los resultados del trabajo realizado en la comunidad.

\section{Objetivo Específico 3}

Orientar al cabildo y líderes de la comunidad la presentación, discusión y aprobación de la Propuesta de estrategias para la conservación del sitio sagrado “Hatun Pukyo".

\section{POBLACIÓN INVOLUCRADA}

La problación involucrada es principalmente la comunidad Cuatro Esquinas dirigidas por el cabildo anual. 


\section{VINCULACIÓN CON EL PLAN NACIONAL DE DESARROLLO "TODA UNA VIDA" Y OTROS NIVELES DE GOBIERNO.}

Las estregias para la conservación del sitio sagrado "Hatun Pukyo" de la comunidad cuatro Esquinas, tiene un enfoque cultural y ambiental, en tal sentido el proyecto contribuye a lineamientos nacionales, provinciales, cantonales y parroquiales.

Tabla 10. Objetivos de los niveles de gobierno.

\section{OBJETIVO PARROQUIAL 1}

Manejar adecuadamente los recursos naturales delimitando la frontera agrícola y expansión urbana a través de campañas de educación y normas de protección ambiental, protegiendo la biodiversidad y fuentes hídricas, para garantizar la calidad de vida de la población.

\section{OBJETIVOS ARTICULADOS AL PDOT DEL MUNICIPIO DE OTAVALO}

Conservar, proteger y restaurar los recursos naturales del Cantón Gestionar el riesgo natural y antrópico en el Cantón

\section{OBJETIVOS ARTICULADOS AL PDOT DEL GOBIERNO PROVINCIAL}

Promover la conservación, restauración e investigación de los ecosistemas estratégicos y su biodiversidad, asegurando el flujo y provisión de bienes y servicios eco sistémico.

Implementar medidas orientadas a la adaptación y mitigación frente a los efectos del cambio climático para reducir la vulnerabilidad social-ambiental. Impulsar la gestión integral de riesgos con enfoque en la reducción de vulnerabilidades e identificación de amenazas.

VINCULACION A LOS TRES EJES DE PRIORIDAD NACIONAL

\begin{tabular}{|l|l|l|}
\hline Estrategia Nacional para la & $\begin{array}{l}\text { Estrategia Nacional para el } \\
\text { lgualdad y la erradicación } \\
\text { de la pobreza }\end{array}$ & $\begin{array}{l}\text { Sustentablidad patrimonial } \\
\text { productiva }\end{array}$
\end{tabular}

Fuente: PDOT SRL (2015-2019).

\section{CONCLUSIONES}

La indagación acerca de la importancia de los sitios sagrados en las diferentes culturas se basó en una amplia revisión bibliográfica de autores tales como, Freire, E., Córdoba, E., Servín, J. entre otros, los que coinciden en la importancia del conocimiento amplio de los problemas culturales y ambientales que afectan 
globalmente a las áreas de patrimonio natural y cultural, especialmente en los pueblos indígenas, trayendo como consecuencia que el proceso de fortalecimiento interno que se ha llevado durante años, no ha sido suficiente para la conservación de la riqueza autóctona existente en cada territorio ancestral.

Se diseñó un procedimiento para la recolección de la información de la comunidad Cuatro Esquinas con relación al sitio sagrado "Hatun Pukyo", que sirvió para estructurar de forma lógica los pasos a seguir en la consecución de los resultados finales, de forma tal, que este procedimiento puede ajustarse a posteriores investigaciones de temas relacionados con la conservación del patrimonio cultural y natural, turismo comunitario, entre otros proyectos.

Finalmente, se proponen un conjunto de estrategias para la conservación del sitio sagrado "Hatun Pukyo", comunidad Cuatro Esquinas, que contienen objetivos actividades, participantes, responsables, periodo de ejecución y presupuesto, las que fueron evaluadas por los expertos seleccionados, dando solución al objetivo de la investigación.

Los resultados de la investigación constituyen material de información para el cabildo de Cuatro Esquinas firmando parte de los documentos oficiales de la comunidad, además, de servir de material de consulta para las nuevas generaciones comunitarias, así como para docentes, estudiantes y personal interesado en problemas de antropología cultural.

\section{REFERENCIAS BIBLIOGRÁFICAS}

Amaru, J. (2012). Cosmovisón Andina. Lima,Perú: Pachayachachiq.

Cachimuel, E. (2018). Propuesta de estrategias para la conservación del sitio sagrado "Hatun Pukyo", comunidad Cuatro Esquinas, parroquia San Rafael de la Laguna. Tesis de grado, Ingeniería en Desarrollo Social y Cultural, Universidad de Otavalo, Ecuador. Tutora Lidia Díaz

Caraballo, C. (2011). Patrimonio cultural: un enfoque diverso y comprometido. Recuperado de: http://www. unesco.

Córdoba, E. (2005). Sitios sagrados y territorio wiwa. Universitas Humanística, (61), 275-286. Colombia. 
Diario La Hora (2019). El patrimonio latente de Otavalo. Consultado el 16 de abril de 2019. Recuperado de https://www.lahora.com.ec/noticia/1101415778/elpatrimonio-latente-de-otavalo)

Diaz, M. (2010). Criterios y conceptos sobre el patrimonio cultural en el siglo XXI. Publicaciones de la UBP, (1), 1-25.

Folleto № 10 (2019). Los pueblos indígenas y el medio ambiente. Consultado el 16 de abril de 2019. Recuperado de https://www.ohchr.org/Documents/Publications/GuideIPleaflet10sp.pdf)

Freire, E. (2012). Investigación de Línea base del Patrimonio Intangible de la Parroquia de Pilahuín del Cantón Ambato, Provincia de Tungurahua (tesis de pregrado). Universidad Tecnológica Israel, Quito, Ecuador.

Sarmiento, F., Cotacachi, C., y Carter, L. (2008). El sagrado Imbakucha: intangibles en la conservación de los paisajes culturales del Ecuador. Recuperado de: http://www.silene.es/documentos/3_Sacred_Imbakucha_esp.pdf

Servín, J. 2013). Los sitios sagrados para los pueblos indigenas. Definición y características. Recuperado de: http://www.seam.gov.py/sites/default/files/13\%20Sitios\%20sagrados\%20para\%20pueblos\%20ind\%C3\%ADgenas.pdf

Troncoso, C. A., y Almirón, A. V. (2005). Turismo y patrimonio. Hacia una relectura de sus relaciones. Aportes y transferencias, 9(1), 56-74

Luque, D., \& Doode, S. (2007). Sacralidad, territorialidad y biodiversidad comcáac (seri). Los sitios sagrados indígenas como categorías de conservación ambiental. Relaciones. Estudios de historia y sociedad, 28(112), 157-184.

Masaquiza, T. (2017). Los sitios sagrados del pueblo Salasaka en la ofercta turística del cantón Pelileo provincia Tungurahua (tesis de pregrado). Universidad Técnica de Ambato, Ambato, Ecuador.

Núñez, M., Cóndor, J., y Loaiza, A. (2003). Los sitios sagrados en los territorios de las nacionalidades y pueblos del Ecuador: Un avance para su focalización. Recuperado de: http://www.siise.gob.ec/siiseweb/PageWebs/Documentos/pubsii_0055.pdf

Varo, F. (2006). El espacio sagrado en la Torah. Recuperado de: https://dadun.unav.edu/bitstream/10171/8608/1/REV_2_01.pdf 
UNESCO (2001). Declaración Universal de la Unesco sobre la Diversidad Cultural. Consultado el 16 de abril 2018. Recuperado de http://www.infoartes.pe/declaracion-universal-de-la-unesco-sobre-la-diversidadcultural-2001/)

UNESCO (2017). Oficina de la UNESCO, Quito. Consultado 12 de abril 2019. Recuperado de http://www.unesco.org/new/es/quito/media-service/singleview/news/reservas_espirituales_de_la_humanidad/ 